\title{
Guided Tissue Regeneration - A Boon to Surgical Periodontal Therapy
}

\author{
${ }^{1}$ Dr. Akhilesh Sankhyayan - Post Graduate, Department of Periodontics, Himachal Dental College, Sundernagar. \\ ${ }^{2}$ Dr. Anil Sharma - Post Graduate, Department of Periodontics, Himachal Dental College, Sundernagar. \\ ${ }^{3}$ Vidushi Jindal - Undergraduate, Universida Catolica San Antonio (UCAM, Murcia, Spain) \\ ${ }^{4}$ Dr. Malvika Thakur (Corresponding author) - Sr. Lecturer, Department of Periodontics, Himachal Dental College, Sundernagar. \\ ${ }^{5}$ Dr. Vikas Jindal - Professor \&amp; Head of Department, Department of Periodontics, Himachal Dental College, Sundernagar. \\ ${ }^{6}$ Ayushi Singla - Intern, Himachal Dental College, Sundernagar.
}

\begin{abstract}
Periodontitis has been a chronic inflammatory disease of the gingiva which eventually result in periodontal pocket formation with loss of the associated periodontal ligament and alveolar bone around teeth. Guided tissue regeneration (GTR), which is often a target for periodontal treatment, has the ability to promote periodontal regeneration. The development of the periodontal attachment is primarily concerned with tissue regeneration.Based on such concept, guided tissue regeneration is being utilized to varying degree of success to restore periodontal defects. In order to remove epithelium as well as gingival corium from the root and/or existing bone walls on the assumption that they interfere with regeneration, barrier techniques have been applied, using elements like expanded polytetrafluoroethylene, polyglactine, polylactic acid, calcium sulfate and collagen.
\end{abstract}

Keywords:- Periodontitis, Guided tissue regeneration, Barrier techniques, Regeneration.

\section{INTRODUCTION}

Repair is indeed the capacity of the body tissues to resolve injury to hard and soft tissue. Regenerative periodontal therapy to fully rebuild supporting tooth tissues that are damaged due to inflammatory periodontal disease or injury is manifested by the development of new cement with the introduction of new periodontal ligament (pdl), collagen fibers and new alveolar bone (Karring etal, 2003)[1]. Numerous treatment procedures, including the use of different types of bone graft, root surface demineralisation, guided tissue regeneration (GTR), growth factors or the use of enamel matrix derivative (EMD) have been used with considerable success to resolve this problem.(Bowers etal 1989[2], Lynch etal 1991[3], Brunsvold \& Mellonig 1993[4], Lowenguth \& Blieden 1993[5], Hammarstrom 1997, Karring etal 2003).

The concept of GTR was introduced by Melcher.[6] GTR treatment involves the application of a biodegradable or non-biodegradable barrier membrane over periodontal abnormalities as well as denuded root surfaces, enabling PDL and bone cells to preferentially recolonise isolated spaces (Karring et al . 2003).
GTR is based upon the assumption of the separation of gingival connective tissue cells from the wound and the prevention of epithelial growth. This method allows cells with regenerative potential to infiltrate the wound site selectively[7]. The root region is then recolonized and converted into a new periodontal support system with the development of new bone, PDL and cementum, by the progenitor cells situated in the residual PDL, adjacent alveolar tissue or blood [9]

GTR Therapy signs are small intrabony defect with twoor three-walled; molar furcation of class II; mobility free defect; circumferential defects; gingival recession of class I or II; and presence of thick gingiva[9].

* Components used in the Scientific Implementation of
Membrane Barrier: 8 to 10 Various forms have been produced for membrane materials.

\section{Non-resorptive membrane :}

- Cellulose filters:

The periodontal ligament, cementum and alveolar bone were stripped from the facial side of the cuspid teeth and the defects were covered with cellulose filters. Regeneration and new attachment of new cementum with insertion of periodontal ligament fibers were seen in histological analysis. Cellulose filters have drawbacks such as exfoliation, premature removal, and need of a second procedure to remove them.

\section{- Expanded polytetrafluoroethylene membranes:}

ePTFE membranes consist of nodes of polytetrafluoroethylene and fibroids of a porosity-different micro-structure. The inertness and tissue compatibility of ePTFE is recognized. Two configurations are available

$\checkmark$ The architecture of the transgingival is used to deal with defects associated with gingiva-like structures.

$\checkmark$ In cases where no contact occurs with the oral system, for example a bony defect, the submerged template is used.

ePTFE augmented with titanium membranes: titanium enhanced ePTFE membranes have been designed to be used in 
situations where a defect anatomy may cause the material to collapse in the defect room, and/or where space is required to regenerate as space efficiency depends on a membrane's mechanical ability to resist collapse.

This membrane is useful in that it prevents the breakdown for some time for proper healing and can be quickly removed. Inconvenience is the second operation needed to remove them, which increases the patient's cost and operating trauma.

\section{Products and equipment resorbable:}

The benefit is to prevent a second procedure to reduce patient illness and costs.

The drawbacks are:

- Exposure material or dehiscence flap may cause problems postoperative tissue management.

- Exposition of material can cause bacterial growth, morphological changes in fibroblast and migration that can result in a regeneration process failure.

- Collapse of the membrane that could result in inadequate space

\section{$>$ Membrane collagen:}

Collagen has many characteristics, including beneficial effects on coagulation and wound healing, regulated crosslinking, low antigenicity, expansion and high tensile strength and fibre-oriented orientation. The development of collagen in different forms can also take place (e.g. sheets, gels, tubes, powders, sponges).

Advantages: minimal complications, strong healing rate, material dehiscence occurrence, tissue perforation, resilience, immune response, sloughing of the tissue.

\section{$>$ Polylactic acid:}

The first resorbable obstacle approved by the Administrative Food and Drug Administration (FDA) for membrane barrier techniques is a bioresorbable matrix barrier consisting of a mixture of polylactic acid that has been softened with citric acid for malleability and facilitating clinical handling (guider). This device is a multi-layered matrix designed to prevent the growth of gingival epithelium apical down.

The material re-estructuring is scheduled for a minimum of 6 weeks to ensure the obstacle function, which then gradually settles. Total resorption takes place at around 12 months.

\section{> Polyglycolic acid and polylactic acid:}

Safe with low inflammatory effects and support of periodontal regeneration. The film attaches the fibers to the soft tissue and removes them from the defect. In the initial healing phases ( 2 to 4 weeks with periodontal defects), the fibre matrix is the main structure component that offers sufficient strength for space creation.
As a barrier membrane is a woven mesh barrier made of polyglactin 910, a polyglycolic acid and polylactic acid copolymer, with a resorption rate of between 30 and 90 days. The findings of several studies challenged polyglactin as a result of the fragmentation in guided tissue regeneration (GTR) procedures. In 14 days the integrity of the mesh is lost. The cervical density between the mesh and the neighboring tooth is not optimal, which allows for the formation of the connective tissue epithelium between the root and the barrier[11].

\section{Polymer organic fluid (Atrisorb):}

A dissolved polymer of lactic acid, poly DL-lactide (PLA) dissolved in N-methyl-2-pyrrolidone (NMP) was tested as a resorbable barrier material. The substance starts as a solution that maintains a solid consistency in the interaction with water or other aqueous solution. The structure of polymers is identical to Vicryl sutures (Ethicon Inc.). Semi rigid, it has the advantage of being rigid enough to be placed but sufficiently flexible to adapt to the defect. Therefore, sutures are not necessary.[12,13] The substance is chemically removed by hydrolyses. The blockage adheres directly to the dental structure. The resorption rate is tested and during critical times, the membrane is present in order to avoid epithelial migration and to isolate the periodontal defect cavity[14].

\section{Calcium sulphate:}

Barriers consisting of calcium sulphate can be put over bone grafts for clot stablisabilisation and for keeping away unwanted tissue. The material is a source of calcium during the early mineralization process and facilitates the preservation of particles.[15,16] This is sold in sterile kits containing exact quantities of medical-grade calcium sulfate powder and a syringe prefilled with Cap Set (Lifecore Biomedical, Chaska, MN). These substances are then mixed together to create a molded paste, which confirms even in the presence of blood the desired shape. Without an inflammatory reaction, calcium sulfate dissolves and does not cause any bacteria or support infections in about 30 days.[17,18]

Adaptability (not to be cut until positioning) and porosity (allows the exchange of fluids, but does not require epithelial and connective tissue passage) are the factors behind the use of GTR [19-24], reduced post-operative pain, coagulant protection at the early stage of recovery, soft fabric development in relation to exposed calcium sulphate, lack of material infection on exposure.

\section{Acellular dermal allografts:}

A new form of cellular human cadaver skin derived from tissue banks is a fairly bioresorbable greasing medium. The drug has undergone an epithelialising and decellularization process to avoid the targets of a rejection response that makes a connective tissue immunologically inactive for an avascular tissue.[12-26] Today, dermal allografts are used as barrier of 
the membrane, mucogingival defects, and for attached gingival formation, a therapy for the osseous resection.

Cellulose mesh oxidized:

The oxidized material is an absorbed, weatherproof dressing which turns into a gelatinous mass, incorporating a membrane into the blood coagulation. Most of the mesh was absorbed after 1 week. The defects were usually healed with 2 $\mathrm{mm}$ slots with no evidence of bleeding with gentle scanning at most places. However, it was concluded that the effectiveness and advantages of cellular mesh oxidized for membrane barrier purposes were not sufficient in one case report.[27,28],

\section{- Growth factor release barrier membrane :}

Growth factors play a crucial role in healing and formation of tissues, recovery, angiogenesesis, chemotaxis and cell development. Different bioactive molecules like PDGF, TGF-1, BMP-2 EMD have shown promising effects for promoting periodontal regeneration.[29] PDGF-BB loaded PLLA membrane has a potential to enhance GTR efficacy in rat's calvarial defects.[30]

\section{- Platelet Rich Fibrin (PRF) membrane:}

Platelet granules are a source of several growth factors that play their role in pathways for the regeneration of hard and soft tissue. PRF offers a good alternative to commercially available membranes because of its economic efficiency, relative safety and autologous nature. Gassling et al. studies have shown better outcomes as membranes are used in conjunction with collagen as a scaffold for human periosteal proliferation. [31]

\section{- Anti-bacterial membranes:}

Antibacterial agents have been applied to avoid bacterial contamination of regenerative wound [29]. A decreased bacterial growth and biofilm formation was demonstrated by $25 \%$ wt of metronidozale benzoato incorporated in the layer interface with epithelial tissues (PLA: GEL+MET)[32]. Amoxicillin or tetercycline incorporation in specific GTR membranes could increase the fixation of periodontal ligament cells when Streptococcus mutans and Aggregatibaccus are oral pathogens [33]

The antibacterial activities of membranes with and without zinc phosphate were compared by Chou et al and demonstrated substantial reduction in actinomycetemcomitans function of membranes with zinc phosphate.A recent research found higher membrane osteogenetic activity on the basis of silver hydroxyapatite - nanocomposite titanium / polyamide relative to e-PTFE. [34]

- Amniotic films (AM);

This is a flimsy, extreme, uncomplicated, avascular composite sheet consisting of three significant materials that are single epithelial, a dense cellular foil and avascular mesenchyme containing basically collagen. The amnion 's storm cellular film essentially has the same cellular coating as the gingiva present in other sections of the body. Amniotic film includes multiple growth factors and a protective appearance of bacterial properties which has minimized scarring. [35]

\section{CONCLUSION}

The theory of GT R is to selectively repopulate the root surface by forming periodontal ligament cells. Ideal teeth for this procedure should have no mobility, sufficient keratinized gingiva, higher interproximal bone height and narrow, deep, 3wall defects. For every GTR treatment, the establishment and stabilization of clot, locations, epithelial cell exclusion, availability of space, neovascularisation and full gingival coverage are preferred. Periodontal restoration also allows esthetics and mastication to be retained.

\section{REFERENCES}

[1]. Deproteinized bovine bone (Bio-Oss ${ }^{\circledR}$ ) and bioactive glass $\left(\right.$ Biogran $\left.^{\circledR}\right)$ arrest bone formation when used as an adjunct to guided tissue regeneration (GTR) An experimental study in the rat Andreas Stavropoulos Lambros Kostopoulos Jens Randel Nyengaard Thorkild Karring published: 01 July 2003 Citations: 59

[2]. Correction of a Large Periradicular Lesion and Mucosal Defect Using Combined Endodontic and Periodontal Therapy: A Case Report.International Journal of Periodontics \& Restorative Dentistry . Aug1995, Vol. 15 Issue 4, p376-383.

[3]. Effects of the Platelet-Derived Growth Factor/InsulinLike Growth Factor-I Combination on Bone Regeneration Around Titanium Dental Implants. Results of a Pilot Study in Beagle Dogs Samuel E. Lynch Daniel Buser Rafael A. Hernandez H.P. Weber H. Stich Christopher H. Fox Ray C. Williams First published:01November1991 .1991vol.62 Issue 11.710

[4]. Brunsvold MA, Mellonig JT Bone grafts and periodontal regeneration.Periodontol 2000. 1993 Feb;1(1):80-91.

[5]. Lowenguth RA, Blieden TM. Periodontal regeneration: root surface demineralization. periodontol 2000: 1993 Feb;1(1):54-68.

[6]. Melcher AH. On the repair potential of periodontal tissues. JPeriodontol. 1976;47:256-60.

[7]. Position paper: periodontal regeneration. (2005) J. Periodontol., 76, 1601-1622.

[8]. Hitti, A. R., Kerns D. G. (2011) Guided bone regeneration in the oral cavity: a review, Open Pathol. J., 5, 33-45.

[9]. Frank, A. Scannapieco. (2005) Periodontal regeneration techniques for treatment of periodontal diseases, Dent. Clin. N. Am., 49, 637-659.

[10]. Al Ruhaimi. Bone graft substitutes: A comparative quantitative histologic review of current osteoconductive 
grafting materials. Int $\mathbf{J}$ Oral Maxillofac Implants. 2001;16(1):105-113.

[11]. Tawil G, Mawla M. Sinus floor elevation using a bovine bone mineral (Bio-Oss) with or without the concomitant use of a bilayered collagen barrier (Bio-Gide): a clinical report of immediate and delayed implant placement. Int $\mathbf{J}$ Oral Maxillofac Implants. 2001; 16(5):713-721.

[12]. Hammerle CH, Jung RE, Feloutzis A. A systematic review of the survival of implants in bone sites augmented with barrier membranes (guided bone regeneration) in partially edentulous patients. J Clin Periodontol 29 Suppl . 2002;3:226-231.

[13]. Liversedge, Kevan W. Use of the buccal fat pad in maxillary and sinus grafting of the severely atrophic maxilla preparatory to implant reconstruction of the partially or completely edentulous patient: Technical note. Int J Oral Maxillofac Implants. 2002;17(3):424428.

[14]. Guarnieri R, Bovi M. Maxillary sinus augmentation using prehardened calcium sulfate: A case report. Int J Periodontics Restorative Dent. 2002;22(5):503-508.

[15]. Block MS, Finger I, Lytle R. Human mineralized bone in extraction sites before implant placement: preliminary results. J Am Dent Assoc.2002;133(12):1631-1638.

[16]. Mc Carthy C, Patel RR, Wragg PF, et al. Dental implants and onlay bone grafts in the anterior maxilla: analysis of clinical outcome. Int $\mathbf{J}$ Oral Maxillofac Implants. 2003;18(2):238-241.

[17]. Mc Carthy C, Patel RR, Wragg PF, et al. Sinus augmentation bone grafts for the provision of dental implants: report of clinical outcome. Int $\mathbf{J}$ Oral Maxillofac Implants. 2003;18(3):377-382.

[18]. Block MS, Degen M. Horizontal ridge augmentation using human mineralized particulate bone: preliminary results. J Oral Maxillofac Surg. 2004;62(9 Suppl 2):6772.

[19]. Block MS, Finger I, Lytle R. Human mineralized bone in extraction sites before implant placement: preliminary results. J Am Dent Assoc. 2002;133(12):1631-1638.

[20]. Mc Carthy C, Patel RR, Wragg PF, et al. Dental implants and onlay bone grafts in the anterior maxilla: analysis of clinical outcome. Int $\mathbf{J}$ Oral Maxillofac Implants. 2003;18(2):238-241.

[21]. Mc Carthy C, Patel RR, Wragg PF, et al. Sinus augmentation bone grafts for the provision of dental implants: report of clinical outcome. Int $\mathbf{J}$ Oral Maxillofac Implants. 2003;18(3):377-382.

[22]. Block MS, Degen M. Horizontal ridge augmentation using human mineralized particulate bone: preliminary results. J Oral Maxillofac Surg. 2004;62(9 Suppl 2):6772 .

[23]. Zijderveld SA, Zerbo IR, Van den Bergh JP, et al. Maxillary sinus floor augmentation using a betatricalcium phosphate (Cerasorb) alone compared to autogenous bone grafts. Int $\mathrm{J}$ Oral Maxillofac Implants.2005;20(3):432-440.
[24]. Sjostrom M, Lundgren S, Nilson H, et al. Monitoring of implant stability in grafted bone using resonance frequency analysis. A clinical study from implant placement to 6 months of loading. Int J Oral Maxillofac Surg. 2005;34(1):45-51.

[25]. Tetsuya N, Yutaka Y, Masakazu M, et al. Effects of bioactive glass on bone augmentation within a titanium cap in rabbit parietal bone. J Periodontol. 2006;77(6):983-989.

[26]. Fiorellini JP, Kim DM, Nakajima Y, et al. Osseo integration of titanium implants following guided bone regeneration using expanded polytetrafluoroethylene membrane and various bone fillers. Int $\mathrm{J}$ Periodontics Restorative Dent. 2007;27(3):287-294.

[27]. Barone A, Covani U. Maxillary alveolar ridge reconstruction with non-vascularized autogenous block bone: clinical results. J Oral Maxillofac Surg. 2007;65(10):2039-2046.

[28]. Ozkan Y, Ozcan M, Varol A, et al. Resonance frequency analysis assessment of implant stability in labial onlay grafted posterior mandibles: a pilot clinical study. Int J Oral Maxillofac Implants. 2007;22(2):235-242.

[29]. George Sam, Baiju Radhamoni Madhavan Pillai. Evolution of Barrier Membranes in Periodontal Regeneration--Are the third Generation Membranes really here?\|A Review. Journal of Clinical and Diagnostic Research. 2014; 8(12): ZE14-ZE17

[30]. Park YJ, Ku Y, Chung CP, Lee SJ. Controlled release of platelet-derived growth factor from porous poly(Llactide) membranes for guided tissue regeneration. J Control Release. 1998;51(2-3):201-11

[31]. Gassling V, Douglas T, Warnke PH, Acil Y, Wiltfang J, Becker ST. Platelet-rich fibrin membranes as scaffolds for periosteal tissue engineering. Clin Oral Implants Res. 2010;21(5):543-49.

[32]. Marco C.Bottino, Vinoy Thomas, Gudrun Schimdt, Yogesh K.Vohra, Tien-Min Gabriel Chu, Michael J.Kowolik et al.Recent advances in the development of GTR/GBR membranes for periodontal regeneration - A materials perspective. Review. Academy of Dental Materials, 2012 ; 28: 703-721.

[33]. Hung SL, Lin YW, Chen YT, Ling LJ. Attachment of periodontal ligament cells onto various antibioticsloaded GTR membranes. Int J Periodontics Restorative Dent. 2005;25(3):265-75.

[34]. Chou AHK, LeGeros RZ, Chen Z, Li YH. Antibacterial effect of zinc phosphate mineralized guided bone regeneration membranes. Implant Dentistry 2007;16:89

[35]. Takeshi Amemyia, Takahiro Nakamura, Toshiro Yamamoto, Shigeru Kinoshita and NarisatoKanamura. Tissue Engineering bt transplantation of oral epithelial sheets cultivated on amniotic membrane for oral mucsal reconstruction. Inflammation and regeneration 2010;30(3):176-180. 